NBER WORKING PAPER SERIES

\title{
ASYMMETRIC DEMAND RESPONSE WHEN PRICES INCREASE AND DECREASE: THE CASE OF CHILD HEALTHCARE
}

\author{
Toshiaki Iizuka \\ Hitoshi Shigeoka \\ Working Paper 28057 \\ http://www.nber.org/papers/w28057 \\ NATIONAL BUREAU OF ECONOMIC RESEARCH \\ 1050 Massachusetts Avenue \\ Cambridge, MA 02138 \\ November 2020
}

The authors thank Makoto Abe, Alistair Munro, and Takeshi Murooka for their suggestions. Shigeoka gratefully acknowledges financial support from the Abe fellowship. All remaining errors are our own. The views expressed herein are those of the authors and do not necessarily reflect the views of the National Bureau of Economic Research.

NBER working papers are circulated for discussion and comment purposes. They have not been peer-reviewed or been subject to the review by the NBER Board of Directors that accompanies official NBER publications.

(C) 2020 by Toshiaki Iizuka and Hitoshi Shigeoka. All rights reserved. Short sections of text, not to exceed two paragraphs, may be quoted without explicit permission provided that full credit, including ( $)$ notice, is given to the source. 
Asymmetric Demand Response when Prices Increase and Decrease: The Case of Child Healthcare Toshiaki Iizuka and Hitoshi Shigeoka

NBER Working Paper No. 28057

November 2020

JEL No. I11,I13,I18,J13

\title{
ABSTRACT
}

This study tests whether demand responds symmetrically to price increases and decreases-a seemingly obvious proposition under conventional demand theory that has not been rigorously tested. Exploiting rapid expansion in municipal subsidies for child healthcare in a difference-indifferences framework, we find evidence against it: when coinsurance, our price measure, increases from $0 \%$ to $30 \%$, the demand response is more than twice that to a price decrease from $30 \%$ to $0 \%$, a result consistent with loss aversion. This result indicates that, while economists and policymakers pay little attention, the price change direction matters, and that welfare analysis should incorporate this direction.

\author{
Toshiaki Iizuka \\ Graduate School of Economics \\ University of Tokyo \\ Bunkyo-ku, Japan \\ toshi.iizuka@gmail.com \\ Hitoshi Shigeoka \\ Department of Economics \\ Simon Fraser University \\ 8888 University Drive, WMC 4653 \\ Barnaby, BC V5A 1S6 \\ CANADA \\ and NBER \\ hitoshi_shigeoka@sfu.ca
}




\section{Introduction}

Under conventional demand theory, a movement along the demand curve between two prices will have the same impact on the quantity demanded regardless of the direction of the movement. That is, the absolute value of the change in demand should be the same whether the price increases from $P 1$ to $P 2$ or decreases from $P 2$ to $P 1$. The aim of this study is to examine this seemingly obvious proposition, which, in our view, has not been rigorously tested.

We believe this is an important question to study. Such asymmetry - if it exists-provides a cautionary note against applying price sensitivity estimates derived from a price change in one direction (e.g., a price increase/decrease) to a price change in the opposite direction (e.g., a price decrease/increase), as a welfare calculation can be substantially biased if such asymmetric responses exist. However, economists and policymakers rarely pay attention to the direction of a price change when they report estimates or use estimates from existing studies. This omission may be due to a lack of data and evidence, as it is quite rare to observe exogenous price changes in opposite directions in a single market. Thus, few studies credibly show that demand responses differ depending on the direction of a price change.

We test asymmetric demand responses in the context of demand for child healthcare using individual-level claims data from Japan. In the last decade, municipalities in Japan have rapidly expanded subsidies for child healthcare, which typically reduce patient cost-sharing from 30\% coinsurance to $0 \%$ (free care). Because many municipalities introduced such subsidies for different age groups at different times, we observe the same price change in opposite directions (either from $0 \%$ to $30 \%$ or from $30 \%$ to $0 \%$ ) even for children of the same age. These price variations allow us to examine whether children (and consequently, their parents) react to price increases in much the same way as they do to price decreases.

As noted before, traditional demand theory proposes that a movement along the demand curve between two prices will have the same impact on the quantity demanded regardless of the price change's direction. However, insights from behavioral economics raise the possibility that this might not be the case. In particular, if individuals are loss averse (Tversky and Kahneman, 1991) and feel more loss from a price increase than gain from a price decrease, the change in healthcare spending can be larger in response to a price increase (from $0 \%$ to $30 \%$ ) than to a price decrease (from $30 \%$ to $0 \%)$. Thus, whether the demand responses are symmetric in price direction is ultimately an empirical question.

Exploiting the unique price changes owing to municipal subsidies in a difference-in-differences framework, we find strong evidence against conventional demand theory. When the price is reduced from $30 \%$ to $0 \%$, outpatient spending per month increases by USD 8.9. In contrast, when the price is 
increased from $0 \%$ to $30 \%$, outpatient spending per month decreases by as much as USD 20.0. The difference between these two estimates is statistically significant at the $1 \%$ level. The loss aversion parameter, which is the ratio of the two estimates, is 2.26 and is statistically different from one at the $5 \%$ level. These results imply that conventional demand theory is rejected in favor of prospect theory. To our knowledge, this is the first paper that rigorously tests symmetric demand responses when prices increase and decrease.

This result has substantial policy implications for optimal design of health insurance and policy evaluation in general. If policymakers determine policy based on a parameter estimated using a price change in the opposite direction, they may overestimate or underestimate the demand response by more than a factor of two.

To further understand what drives the asymmetric demand response, we divide demand based on the type of service received: medication, consultation fees, laboratory tests, and nonsurgical procedures. We find that most of the asymmetric demand response is driven by medication: outpatient spending per month increases by only USD 5.7 for price decreases, while it decreases as much as USD 10.2 for price increases.

Finally, as a separate note, we observe substantial intertemporal substitution before and after the price change. This pattern reveals that some children (and hence, parents) anticipate the upcoming price change and behave strategically by delaying or rushing visits; this intertemporal substitution is concentrated within one month around the price change. We observe larger intertemporal substitution when the price increases (rushing) than when the price decreases (delaying), which is also consistent with short-term loss aversion.

Ours is not the first study to examine asymmetric demand responses. In particular, using scanner or sales data, studies in the marketing literature examine how price increases and decreases from a reference price impact the quantity demanded (e.g., Kalwani et al., 1990; Krishnamurthi et al., 1992; Putler, 1992; Kalyanaram and Winer, 1995; Bell and Lattin, 2000; Han et al., 2001; Mazumdar et al., 2005). In general, these studies find that consumers are more sensitive to price increases (losses) than price decreases (gains). However, our study has several advantages. First, because patients face only two prices (either $0 \%$ or $30 \%$ ) that stay the same without a policy change, the reference price in our case is clearly defined; past studies arbitrarily use a past price as the reference price (e.g., Hardie et al., 1993). Second, the magnitude of the price change in our study is exactly the same in both directions $(\Delta=30 \%)$, which is particularly helpful for directly testing conventional demand theory's prediction. Third, we can distinguish the short- and long-term demand responses. In contrast, past studies were able to examine only short-term demand fluctuations because prices in a retail context frequently go up and down. Fourth, to our knowledge, ours is the 
first study to examine asymmetric demand responses in terms of healthcare. In this regard, this study broadly contributes to the literature on behavioral health economics (see Chandra et al., 2019 and Rice, 2013 for reviews).

Finally, this study also contributes to the small but growing body of literature that examines intertemporal substitution in healthcare (Einav et al., 2015; Cabral, 2017; Lin and Sack, 2019). Since these studies exploit the non-linear structure of health insurance (either the deductible or coverage maximum), they can only examine intertemporal substitution for price changes in one direction. ${ }^{1}$ In contrast, we can examine intertemporal substitution for price changes in both directions.

\section{Theoretical Underpinnings}

This section discusses theoretical considerations that explain (a)symmetric demand responses when prices change by the same amount but in opposite directions.

Classical demand theory: As noted in the Introduction, classical demand theory implies that a price change of the same size will have the same impact on demand (with opposite signs) regardless of the direction of the price change. Figure 1 illustrates the textbook case of a consumer's decision, where the consumer chooses the amounts of two goods, healthcare service $Q_{h}$ and a composite good $Q_{c}$, given the prices of the two goods $\left(P_{h}\right.$ and $\left.P_{c}\right)$ under a budget constraint. The initial prices and quantities of the two goods are given by $\left(P_{h}^{0}, Q_{h}^{0}\right)$ and $\left(P_{c}^{0}, Q_{c}^{0}\right)$, respectively. If the price of healthcare service increases from $P_{h}^{0}$ to $P_{h}^{1}$, its quantity will decrease from $Q_{h}^{0}$ to $Q_{h}^{1}$ based on the income and substitution effects. Now, suppose that the change in the price of healthcare service is reversed from $P_{h}^{1}$ to $P_{h}^{0}$. Then, based on classical demand theory, the quantity of healthcare service will return to the original quantity, $Q_{h}^{0}$, from $Q_{h}^{1}$. That is, the absolute value of the impact of the price change on demand should be the same regardless of the direction of the price change.

Prospect theory: A notable alternative to classical demand theory is prospect theory (Kahneman and Tversky, 1979), which incorporates psychological factors into decision-making. Unlike classical demand theory, prospect theory suggests that the magnitude of the demand response may not be symmetric. The basic assumption of prospect theory is that perceived utility or value depends on a "reference state," and the utility loss from being in a worse state is greater than the utility gain from being in a better state, even when the magnitude of the deviation from the reference state is the same in both directions. This phenomenon is known as loss aversion. In our context, this implies that the utility loss from a price increase is greater than the utility gain from a price decrease

\footnotetext{
${ }^{1}$ For example, Lin and Sack (2019) document that people who reach their deductible, leading to low cost-sharing, spend more in the last month of the coverage year as they anticipate the price will increase the next month when the deductible is reset.
} 
even when the size of the price change is the same. This, in turn, leads to a prediction that the magnitude of the quantity change will be greater when the price increases from $P_{h}^{0}$ to $P_{h}^{1}$ than when it decreases from $P_{h}^{1}$ to $P_{h}^{0}$.

Alternative explanation — asymmetry in price information: The information that consumers have about price changes may also result in asymmetric demand responses. For example, suppose those with free care visit doctors often and, as a result, learn about price increases (from $0 \%$ to $30 \%$ ), but those who face $30 \%$ cost-sharing do not visit doctors often and are unaware of price decreases (from $30 \%$ to $0 \%$ ). If this is true, demand may respond more quickly to price increases than price decreases because of asymmetric information among consumers.

We believe that this is less likely to be a major factor in our case for two reasons. First, children visit doctors very often whether they are fully subsidized or not; in our data, children visit doctors an average of 9.92 times per year even when they do not receive subsidies. Second, it is common for municipalities to inform parents in advance by mail if there is a change in subsidy coverage. Thus, parents in this market are generally well informed about price changes in both directions.

\section{Background}

\subsection{The Japanese health insurance system}

We briefly summarize the Japanese health insurance system as it relates to our study (see, Ikegami and Campbell, 1995; Kondo and Shigeoka, 2013 for details). Residents in Japan are covered by the national health insurance scheme. Because enrollment in this scheme is mandatory, there is no issue regarding selection into health insurance in this market. Medical providers are paid by fee-forservice for outpatient services, and all receive the same fee for the same service based on the national fee schedule set by the government. Patients pay coinsurance, which is set nationally at $30 \%$, except for those above age 70 and below age 6 . As we discuss in the next section, many municipalities provide subsidies for child healthcare that cover the patient's out-of-pocket costs, which often reduce children's cost-sharing to zero. There is a stop-loss after a child spends approximately 800 USD per month out-of-pocket for those in the regular income category, but less than $0.1 \%$ of the personmonths in our data exceed the stop-loss. This is because costly hospitalization is rare among children in this age group. Private health insurance that covers patients' out-of-pocket costs is virtually nonexistent in Japan (OECD, 2004). As a result, municipal subsidies affect the price of care faced by children. 


\subsection{Municipal subsidies and price variations}

Over the last decade, municipalities in Japan have drastically expanded subsidies for child healthcare, which typically reduce children's out-of-pocket costs from $30 \%$ to zero. ${ }^{2}$ Figure 2 plots the share of municipalities in our insurance claims data described later by maximum age for outpatient care subsidy eligibility in the period April 2005-March 2015, illustrating the rapid expansion. The figure clearly shows that the subsidy expanded rapidly to older individuals in the last decade. For example, none of the municipalities provided a subsidy up to 15 years of the age in April 2005, the beginning of the sample period. However, this number reached nearly $80 \%$ by the end of our sample period a decade later. ${ }^{3}$

These municipal subsidies provide ideal price variations for testing the implications of the alternative theories discussed in Section 2. First, since each municipality determines whether and when to provide a subsidy and the ages it covers, prices faced by children substantially vary by municipality, time, and the child' age. Second, there are price changes in both directions, as subsidies expand (prices “decrease” from 30\% to 0\%) and expire (prices "increase” from $0 \%$ to 30\%). Among a total of 2,604 changes in subsidy status in the municipality-age-time cell in our insurance claims data, 1,858 changes are subsidy expansions (price “decreases”), whereas 746 changes are subsidy expirations (price "increases"). Third, the magnitude of the price changes is exactly the same in both directions, which is particularly helpful for directly testing conventional demand theory's prediction, as discussed in Section 2.

\section{Data}

\subsection{Description of data}

We use two main data sets in this study. ${ }^{4}$ The first is information on municipal subsidies. For each municipality, we hand-collected the subsidy details, including the subsidy amount (e.g., free care), maximum age for which the subsidy is provided, whether the subsidy is in kind or a refund, and whether there is an income eligibility requirement, through a variety of sources, including municipality web pages, local newspapers, and municipal ordinances. The data cover the period from April 2005 to March 2015 at the monthly level and include all municipalities in Japan’s six largest

\footnotetext{
${ }^{2}$ In this study, we focus on the most common form of child healthcare subsidy, which reduces patient cost-sharing from $30 \%$ to $0 \%$.

${ }^{3}$ The small jump in April 2008 is explained by the fact that the central government expanded the eligibility age for the national-level subsidy from three to six years (the start of primary school). This national-level subsidy expansion eased the budgetary burden on municipalities, as part of the cost to provide free care for children below age six was covered by the central government, allowing municipalities to expand coverage to higher ages.

${ }^{4}$ These are the same data used in Iizuka and Shigeoka $(2018,2020)$.
} 
prefectures, resulting in a total of 294 municipalities. ${ }^{5}$ In this study, we focus on 165 municipalities that have either $0 \%$ or $30 \%$ coinsurance rates. ${ }^{6}$

The second data set includes individual outpatient spending drawn from monthly insurance claims data provided by JMDC Inc. JMDC Inc. collects and analyzes administrative insurance claims data on behalf of large insurers. These data have been used in previous studies, including lizuka (2012), Fukushima et al. (2016), and Iizuka and Shigeoka (2018, 2020).

JMDC data consist of administrative enrollment data and claims data. For each person, enrollment data consist of patient ID, gender, age, and municipality of residence. The age and municipality of residence in each month are crucial in this study because the level of cost-sharing is uniquely determined by municipality, age, and time. The claims data report monthly outpatient spending, including months of no utilization. ${ }^{7}$ Specifically, the claims data contain the year-month of the visit and line-by-line medical services received, including diagnoses (ICD10), types of services, quantity of each service, and fees charged for each service based on the national fee schedule. The unit of claims data in Japan is monthly, as medical institutions are reimbursed on a monthly basis. A unique patient ID links the enrollment and claims data. One drawback—albeit common for insurance claims data — is that, except gender and age of children, the data do not include individual characteristics such as parental education, household income, and family structure (e.g., number of children or siblings).

Our data cover a period of 10 years between April 2005 and March 2015 (120 months). We limit our sample to 6-15-year-olds since we have few observations without subsidy below age 6 and with subsidy above age 15 . This is because most municipalities already provided a subsidy up to the age of 6 years (start of primary school) at the beginning of our sample period, and most municipalities do not provide a subsidy beyond the age of 15 years (end of junior high school) at the end of our sample period (see Figure 2).

\subsection{Summary statistics}

Table 1 presents the summary statistics of selected variables in the main sample at the individual and person-month levels in Panels A and B, respectively. There is a total of 59,775 individuals at the individual level (Panel A). At least one subsidy change is experienced by $16.6 \%$ of them: $15.5 \%$ experience at least one subsidy expansion (from $30 \%$ to $0 \%$ ) and $5.2 \%$ experience at least one expiration (from 0\% to 30\%). Panel B of Table 1 reports some key variables at the unit

\footnotetext{
${ }^{5}$ There was a total of 47 prefectures and 1,719 municipalities in Japan as of January 2015.

${ }^{6}$ Iizuka and Shigeoka $(2018,2020)$ utilize other types of price variations, including small copayments (e.g., $2 \mathrm{USD} /$ visit and $5 \mathrm{USD} / \mathrm{visit}$ ) and $10 \%$ and $15 \%$ coinsurance rates.

${ }^{7}$ The data do not, however, include dental claims or inpatient food and housing costs, which are relatively small.
} 
level of our analysis (person-month); there is a total of 2,027,910 person-months over the sample period of 120 months. Children spend 60.8 USD per month, including zero-spending, and 149.9 USD per month conditional on at least one visit. Out-of-pocket payment per visit without subsidy is 22.3 USD, which gauges the magnitude of the financial burden on individuals if no subsidy is available.

\subsection{Event study}

We first graphically explore the pattern of demand responses using an event study. We normalize the spending data around the change in the subsidy status separately for price increases and price decreases. Then, using individuals who experience price increases and those who experience no price change, we run a simple individual-level fixed effects model that includes interaction terms between the subsidy status and a series of dummies for each month, ranging from 12 months prior to the price increase to 12 months after the change ( $T=-12$ to +11 , where $T=0$ is the month of the price increase). ${ }^{8}$ We then plot the estimates of the interaction terms in a figure. The regression model additionally controls for age and time fixed effects (both in months). We follow the same process for price decreases.

Figure 3 presents the results of the event study for outpatient spending separately for price decreases (subsidy expansion) and price increases (subsidy expiration). The reference month is three months before the change in subsidy status $(T=-3)$. The scales of the $y$-axis are set as the same so that the two figures for opposite price change directions are visually comparable.

We summarize three important facts shown by these figures. First, there are long-lasting demand responses to price changes in both directions, and the estimates take completely opposite signs for opposite price change directions. The long-term estimate for price decreases is roughly USD 10, whereas that for price increases is roughly USD 20. This simple figure already indicates that the long-term demand response is larger for price increases than price decreases.

Second, there are short-run demand responses in both price change directions, as indicated by a surge (in the case of price increases) and a drop (when prices decrease) in outpatient spending just before $T=0$. Interestingly, we also observe offsetting spending immediately after $T=0$. These patterns reveal that some children (and hence, parents) anticipate upcoming price changes and behave strategically by delaying or rushing visits. As we include age and time fixed effects (both in months), this difference is not driven by a particular age or year-month effect, such as expiration of a subsidy after graduation from junior high school.

Finally, the short-run demand response immediately before a price change appears

\footnotetext{
${ }^{8}$ We exclude observations if there is another price change within two months of the observation. For example, if there is another price change at $T=10$ for an individual, we include data only up to $T=7$ for the individual.
} 
substantially larger than that immediately after a price change, as if demand overshoots before a price change. This “overshooting” is especially larger for price increases (graph on the right); the surge before the price increase at $T=0$ is much larger than the drop just after the price increase. This may imply that children purchased healthcare services more during the pre-price change period than they could intertemporally substitute between the pre and post periods.

\section{Empirical Framework}

\subsection{Stylized demand responses and hypotheses to be tested}

The event study presented in Section 4.3 indicates that 1) price changes in both directions have long-lasting effects on demand, 2) there is a short-term demand response immediately before a price change, and 3) the short-term response is greater before than after the price change. The goal of our empirical model is to estimate parameters relevant to these observations in a parsimonious way. Towards this end, Figure 4 presents a stylized model of demand responses that incorporates all these features. The figure on the left corresponds to price decreases and the one on the right is for price increases.

We first focus on long-term responses. The event study indicated that a price reduction from $30 \%$ to $0 \%$ clearly increases demand after the price change, and the impact is long lasting. In the figure on the left, we call this effect a "long-term response (1)" and parameterize it as $\beta^{d e c}$. In a similar vein, the long-term effect of price increases (1)') in the figure on the right can be expressed as $\beta^{\text {inc }}$. Conventional demand theory predicts that $\beta^{\text {dec }}$ and $\beta^{\text {inc }}$ have the same magnitude because a movement along the demand curve between two prices will have the same impact on quantity demanded regardless of the direction of the price change. In contrast, prospect theory indicates that $\beta^{\text {dec }}$ is smaller than $\beta^{\text {inc }}$. Therefore, our first set of null and alternative hypotheses is as follows.

\section{Hypothesis 1 (symmetry in long-term responses): $\left|\beta^{\text {dec }}\right|=\left|\beta^{\text {inc }}\right|$ \\ Hypothesis 1' (greater response to price increases): $\left|\beta^{\text {dec }}\right|<\left|\beta^{\text {inc }}\right|$}

If null hypothesis 1 is rejected in favor of hypothesis 1', we conclude that, in favor of prospect theory, conventional demand theory does not hold, at least in our setting. In this case, the ratio of the two estimates $\left(\beta^{i n c} / \beta^{\text {dec }}\right.$ ) can be viewed as the loss aversion parameter. This first hypothesis is our main interest in this study.

Next, we turn to short-term responses. Once again, we first discuss the figure on the left for price decreases. The event study indicated that there are short-term demand responses immediately before the price change at $T=-1$ and immediately after the price change at $T=0$. We term the former as the "anticipatory effect (2),", represented by $\gamma_{-1}^{d e c}$, and the latter as the "offset effect (3) )," with 
the parameter $\gamma_{0}^{d e c}$. The anticipation effect, $\gamma_{-1}^{\text {dec }}$, may arise if people cut back on healthcare in anticipation of lower future prices. Such a temporary demand reduction may also result in the offset effect, $\gamma_{0}^{d e c}$, if individuals can delay their purchase until the price is reduced at $T=0$. If both anticipation and offset effects are present, we can see that individuals intertemporally substitute consumption.

The short-term demand response for price increases can be characterized in the same way, with analogous parameters (see the figure on the right in Figure 4). In this case, the anticipation effect, $\gamma_{-1}^{\text {inc }}$, may imply that individuals stock up on health care in anticipation of higher future prices. This effect may be offset by $\gamma_{0}^{\text {inc }}$ after the price increase if people cut back because they have fewer unmet needs.

We test whether anticipatory and offset effects exist in both price directions.

Hypothesis 2 (non-existence of anticipatory effect and offset effect):

$$
\gamma_{-1}^{\text {dec }}=0, \gamma_{0}^{\text {dec }}=0, \gamma_{-1}^{i n c}=0, \gamma_{0}^{i n c}=0
$$

Finally, we can examine whether the impact of the anticipatory effect (2)) is completely canceled by the offset effect (3). This is equivalent to examining whether "over-shooting (4))," which is the difference between the anticipation effect and the offset effect, that is $\left(\left|\gamma_{-1}^{d e c}\right|-\left|\gamma_{0}^{d e c}\right|\right)$, is equal to zero. If "over-shooting” exists, it implies that when prices decrease, children spend less during the pre-price change period than they intertemporally substitute. Similarly, we can define the overshooting for the price increase (4)') by $\left(\left|\gamma_{-1}^{i n c}\right|-\left|\gamma_{0}^{i n c}\right|\right)$. We are interested in whether such overshooting exists in both price directions and if there is asymmetry in overshooting.

Hypothesis 3 (non-existence of overshooting): $\left|\gamma_{-1}^{\text {dec }}\right|-\left|\gamma_{0}^{\text {dec }}\right|=0,\left|\gamma_{-1}^{\text {inc }}\right|-\left|\gamma_{0}^{\text {inc }}\right|=0$

$$
\text { Hypothesis } 4 \text { (symmetry in overshooting): }\left|\gamma_{-1}^{d e c}\right|-\left|\gamma_{0}^{d e c}\right|=\left|\gamma_{-1}^{i n c}\right|-\left|\gamma_{0}^{i n c}\right|
$$

We reiterate here that our main interest is the long-term response, that is, hypothesis 1 .

\subsection{Empirical model}

We estimate an empirical model that allows us to identify the key parameters discussed in the previous section, using longitudinal claims data in a difference-in-differences framework. Specifically, our basic estimation equation is:

$$
\begin{gathered}
Y_{\text {iamt }}=\alpha+\beta^{\text {dec }} \operatorname{dec}_{\text {iamt }}+\beta^{i n c} i n c_{i a m t}+\sum_{k=-K}^{k=K-1} \gamma_{k}^{d e c} 1\left(D^{d e c}=k\right)+\sum_{k=-K}^{k=K-1} \gamma_{k}^{i n c} 1\left(D^{i n c}=\right. \\
k)+\omega X_{m t}^{\prime}+\delta_{a}+\pi_{t}+\rho_{m}+\theta_{i}+\varepsilon_{\text {iamt }}-[1]
\end{gathered}
$$

where $Y_{\text {iamt }}$ is the outpatient spending of child $i$ whose age is $a$ (measured in months) at time $t$ (year- 
month) and is living in municipality $m . \delta_{a}, \pi_{t}$, and $\rho_{m}$ are fixed effects for age, time, and municipality, respectively. ${ }^{9}$ In addition, $\theta_{i}$ represents the individual fixed effects, which captures the child's unobserved time-invariant characteristics and addresses the compositional changes in the unbalanced panel data. We also control for two time-varying municipality variables, $X_{m t}$, a dummy that equals one if the subsidy is in kind rather than a refund and zero otherwise, and another dummy variable that equals one if there is an income restriction on subsidy eligibility and zero otherwise.

The variable $d e c_{i a m t}$ is the indicator for a price decrease, which equals zero before $i$ experiences a price reduction and equals one in all periods after a price decrease, even if the subsidy is expired. We define inc $_{\text {iamt }}$ similarly. ${ }^{10}$ For example, suppose an individual's coinsurance rate is initially $30 \%$ at age 6 , goes down to $0 \%$ at age 10 , and increases to $30 \%$ at age 12 . Then, dec $_{\text {iamt }}$ equals zero before age 10, and one at age 10 and thereafter. The value of $i n c_{\text {iamt }}$ is zero before age 12, and one at age 12 and thereafter. Currie et al. (2015) employ a similar strategy to examine the asymmetric effects of opening and closing toxic plants on housing values. $\beta^{d e c}$ and $\beta^{i n c}$ capture the long-term effect of price decreases and increases in spending, respectively, as they are illustrated in our stylized model. These parameters are identified from within individual variations before and after a price change, along with a control for the time trend to which individuals in other municipalities without a price change contribute. Note that we estimate one coefficient each for price increases $\left(\beta^{i n c}\right)$ and price decreases $\left(\beta^{d e c}\right)$, instead of estimating age specific values. Although this is a simplification, previous work using the same data (Iizuka and Shigeoka, 2018) shows that the effect of a price change is quite similar across children between ages 6 and 15, which supports our modeling approach.

The indicator variable $1\left(D^{d e c}=k\right)$ equals one in the $k$ th month from the price decrease and zero otherwise. $\gamma_{k}^{\text {dec }}$ captures the short-run deviation in spending in month $k$ from the long-run average spending. $\gamma_{k}^{\text {dec }}$ corresponds to the anticipation effect (2) and offset effect (3) in Figure 4. $1\left(D^{i n c}=k\right)$ can be defined similarly and $\gamma_{k}^{i n c}$ is interpreted accordingly.

We first experiment with $K$ being equal to one (i.e., allowing the short-run deviation to exist one month before and after the price change) and then expand $K$ to two months. We find that the anticipation and offset effects become statistically significant only in the month of the price change ( $k$ $=0$ ) and one month before the price change $(k=-1)$, as seen in Figure 3. Thus, we set $K$ equal to one, and the resulting estimation equation is written as:

\footnotetext{
${ }^{9}$ Note that we still include $\delta_{a}$ at the monthly level to account for any age in month-specific effects (e.g., graduation from junior high school).

${ }^{10}$ Note that this method of constructing variables in our data only makes sense when the changes in an individual's subsidy status are less than or equal to two. Thus, we remove 921 individuals (1.45\%) who experience more than two changes in subsidy status.
} 


$$
\begin{gathered}
Y_{\text {iamt }}=\alpha+\beta^{\text {dec }} \operatorname{dec}_{\text {iamt }}+\beta^{\text {inc }} \text { inc }_{\text {iamt }}+\gamma_{-1}^{\text {dec }} 1\left(D^{\text {dec }}=-1\right)+\gamma_{0}^{\text {dec }} 1\left(D^{\text {dec }}=0\right)+ \\
\gamma_{-1}^{\text {inc }} 1\left(D^{\text {inc }}=-1\right)+\gamma_{0}^{i n c} 1\left(D^{\text {inc }}=0\right)+\omega X_{m t}^{\prime}+\delta_{a}+\pi_{t}+\rho_{m}+\theta_{i}+\varepsilon_{\text {iamt }}-[2]
\end{gathered}
$$

We estimate this equation using ordinary least squares (OLS). ${ }^{11}$ Standard errors are clustered at the municipality level to account for serial correlation in the error terms within municipalities.

The identifying assumption in our difference-in-differences strategy is that there are no unobserved municipality-specific changes that are (1) correlated with subsidy changes in the municipality and (2) correlated with municipality-specific changes in healthcare utilization. For example, if municipalities in better financial condition are more likely to implement subsidy expansion whereas income effects simply increase utilization, our estimates may be biased upward.

To address this concern, we adopt two approaches. First, the event study in Section 4.3 already shows there are no systematic differences in the pre-trend between the treated and control municipalities before changes except for the anticipation effect. Second, we add time-bymunicipality fixed effects (with time measured in months) to examine the robustness of our baseline estimates. This specification is most stringent, as these fixed effects capture the average effect of municipality-specific policy changes or events in a particular month, if any, such as income transfers, other subsidies, or business cycles. ${ }^{12}$

\section{Results}

\subsection{Main results}

We report estimation results from equation [2] and the results of hypotheses tests in Table 2. We first focus on the long-term demand responses (hypothesis 1). Spending increases (1) by USD 8.89 when prices decrease, whereas spending decreases (1)') by as much as USD 20.0 when prices increase, more than double the change for a price decrease. These results indicate that children react much more strongly to price increases than price decreases. Note that although a price increase from $0 \%$ to $30 \%$ starts from a “zero price,” this does not explain the differential demand responses, because a price decrease also includes a zero price when the price decreases from $30 \%$ to $0 \%$. The difference between the two estimates is USD 11.1 and is highly statistically significant at the 1\% level. These results are consistent with loss aversion but not with conventional demand theory. The loss aversion parameter, which is the ratio of the two estimates, is 2.26. Previous studies using lab

\footnotetext{
${ }^{11}$ In our previous work (Iizuka and Shigeoka, 2018, 2020), we used OLS and alternative functional forms, including one- and two-part generalized linear models, and find the estimates are almost identical.

${ }^{12}$ Additionally, one may be concerned that sicker children may move to a municipality that offers free care. To alleviate this concern, we estimated a conditional logit model that examines whether children migrate to a municipality that provides free care and found little evidence to support this (see Iizuka and Shigeoka, 2018).
} 
experiments typically estimate the loss aversion parameter as just over 2 (e.g., Tversky and Kahneman, 1991), which is similar to our results. The null hypothesis that the loss aversion parameter is equal to one (i.e., there is no loss aversion) is rejected at the $5 \%$ level $(p=0.0197){ }^{13}$

This result has substantial policy implications. If policymakers determine policy based on a parameter estimated by a price change in the opposite direction, they may overestimate or underestimate the demand response by more than a factor of two. Although previous studies pay little attention to a price change's direction, the direction of a price change does matter.

We next examine the short-term demand responses. First, there is substantial intertemporal substitution in both price directions, as we find both the anticipation and offset effects are statistically significant (hypothesis 2). Interestingly, the magnitude of the anticipation effect is larger than that of the offset effect regardless of the price direction (hypothesis 3). These results may indicate that individuals overreact to anticipated price changes and purchase more/less (when prices increase/decrease) than they intertemporally substitute. ${ }^{14}$ As a result, there is significant overshooting in both price change directions. ${ }^{15}$ We also find that asymmetry exists in overshooting (hypothesis 4): overshooting for a price increase (USD 21.25) is much larger than that for a price decrease (USD 9.41), and the difference is statistically significant at the $1 \%$ level.

Overall, we find that children respond differentially to price increases and decreases. In general, they respond more strongly to price increases than price decreases, which is consistent with loss aversion. In particular, we find large price asymmetry in long-term demand responses. We also find asymmetry in overshooting in the short run. Appendix Table A1 reports the results from a specification that adds time-by-municipality fixed effects to equation (2) and finds qualitatively similar results.

\subsection{Heterogeneity}

To further understand what drives the asymmetric demand responses, we examine heterogeneity by service type. We divide spending into six service types: medication $(54.1 \%)^{16}$, consultation fees (23.6\%), laboratory tests (17.4\%), non-surgical procedures (5.8\%), surgical procedures (3.2\%), and all else (1.2\%). ${ }^{17}$ Table 3 reports the results for the four largest categories, which equal $95.6 \%$ of

\footnotetext{
${ }^{13}$ The standard errors are calculated using the delta method.

${ }^{14}$ As reported in Table 2, for a price decrease, the anticipation effect is USD 15.19 whereas the offset effect is only USD 5.78. This pattern is stronger for price increases; the anticipation effect is USD 28.22, whereas the offset effect is only USD 6.97.

${ }^{15}$ Lin and Sack (2019) also find that both anticipation and offset effects exist, and the former exceeds the latter.

${ }^{16}$ We exclude outliers from the sample (i.e., growth hormone injections) as they are extremely expensive (on average USD 3,334) relative to other medications and substantially increase the variance.

${ }^{17}$ Medication includes fees for prescribing and dispensing medications, including pharmacy fees, and accounts for more than half of total spending.
} 
total spending. The corresponding figures are presented in Figure 5.

Panel A of Table 3 presents the long-term demand response by service type. It shows that medication contributes most to the long-term asymmetry observed at the aggregate level: whereas outpatient spending increases by only USD 5.67 for price decreases, it decreases as much as USD 10.2 for price increases. The difference is statistically significant at the $1 \%$ level. We note that although we find a negative sign for consultation, the magnitude is relatively small.

Panel B of Table 3 presents the short-term demand response by service type. First, we find anticipation effects in both directions (rows 1 and 3) for all service types. In particular, we find large anticipation effects for price increases (row 3) in medication (USD 12.56)—implying the stockpiling of storable goods - and in laboratory testing (USD 7.82). By contrast, the magnitude of the offset effect (rows 2 and 4) is relatively small in all service types and in both price change directions. While we observe little overshooting for price decreases (row 5), we find substantial overshooting for price increases (row 6) for medication (USD 10.67) and laboratory testing (USD 6.25). As a result, asymmetry in overshooting is observed only for medication and laboratory testing (row 7).

The large overshooting in medication may indicate that future price increases induce consumers to purchase additional medications (such as additional days of prescriptions or different types of medications) that may not necessarily be intertemporally substituted. ${ }^{18}$ Our results regarding medications are consistent with Chandra et al. (2010), who document that the elderly stockpile prescription drugs just before a small increase in copayment. We further contribute to the literature by showing that overshooting exists and is especially larger for price increases than price decreases.

\section{Conclusion}

This study tests whether the demand response differs when prices increase and decrease in the context of child healthcare. Economists and policymakers pay little attention to the direction of a price change when they report and utilize estimates. This omission is not surprising because it is quite rare to observe exogenous price changes in opposite directions in the same market. Exploiting the rapid expansion in subsidy for child healthcare in Japan, where we observe the same price changes in opposite directions, we find evidence against the conventional demand theory: when price increases from $0 \%$ to $30 \%$, demand decreases more than twice as much as it increases when price decreases from $30 \%$ to $0 \%$, a result consistent with loss aversion. This result suggests the direction of a price change does matter, and welfare analysis should incorporate price change direction. Testing whether similar asymmetric demand responses exist in other goods is one interesting avenue for

\footnotetext{
${ }^{18}$ We abstract from whether this effect is induced by the patient or physician. See, for example, Iizuka $(2007,2012)$ for studies that attempt to disentangle these two effects.
} 
future research.

\section{References}

Bell, David R., and James M. Lattin. (2000) "Looking for loss aversion in scanner panel data: the confounding effect of price response heterogeneity.” Marketing Science 19: 185-200.

Cabral, Marika. (2017) “Claim timing and ex post adverse selection.” Review of Economic Studies 84: $1-44$.

Chandra, Amitabh, Jonathan Gruber, and Robin McKnight. (2010) "Patient cost-sharing and hospitalization offsets in the elderly.” American Economic Review 100(1): 193-213.

Chandra, Amitabh, Benjamin Handel, and Joshua Schwartzstein. (2019) "Behavioral economics and health-care markets.” In Handbook of Behavioral Economics: Foundations and Applications 2, edited by B. Douglas Bernheim, Stefano DellaVigna, and David Laibson. Amsterdam: Elsevier/North-Holland.

Currie, Janet, Lucas Davis, Michael Greenstone, and Reed Walker. (2015) "Environmental health risks and housing values: Evidence from 1,600 toxic plant openings and closings.” American Economic Review 105(2): 678-709.

Einav, Liran, Amy Finkelstein, and Paul Schrimpf. (2015) “The response of drug expenditure to nonlinear contract design: Evidence from Medicare Part D.” The Quarterly Journal of Economics 130(2): 841-899.

Fukushima, Kazuya, Sou Mizuoka, Shunsuke Yamamoto, and Toshiaki Iizuka. (2016) "Patient cost sharing and medical expenditures for the Elderly.” Journal of Health Economics 45: 115130.

Han, Sangman, Sunil Gupta, and Donald R. Lehmann. (2001) "Consumer price sensitivity and price thresholds.” Journal of Retailing 77(4): 435-456.

Hardie, Bruce G. S., Eric J. Johnson, and Peter S. Fader. (1993) “Modeling loss aversion and reference dependence effects on brand choice.” Marketing Science 12(4): 378-394.

Iizuka, Toshiaki. (2007) "Experts' agency problems: Evidence from the prescription drug market in Japan.” RAND Journal of Economics 38(3): 844-862.

Iizuka, Toshiaki. (2012) "Physician agency and adoption of generic pharmaceuticals." American Economic Review 102(6): 2826-2858.

Iizuka, Toshiaki, and Hitoshi Shigeoka. (2018) "Free for children? Patient cost-sharing and healthcare utilization.” NBER Working Paper No. 25306.

Iizuka, Toshiaki, and Hitoshi Shigeoka. (2020) "Is zero a special price? Evidence from child healthcare.” Unpublished manuscript.

Ikegami, Naoki, and John C. Campbell. (1995) “Medical care in Japan.” New England Journal of Medicine 333: 1295-1299.

Kahneman, Daniel, and Amos Tversky. (1979) "Prospect theory: An analysis of decision under risk.” Econometrica 47(2): 263-292.

Kalwani, Manohar U., Chi Kin Yim, Heikki J. Rinne, and Yoshi Sugita. (1990) “A price expectations model of customer brand choice.” Journal of Marketing Research 27(3): 251-262.

Kalyanaram, Gurumurthy, and Russell S. Winer (1995) "Empirical generalizations from reference price research.” Marketing Science 14(3): G161-G169.

Kondo, Ayako, and Hitoshi Shigeoka. (2013) "Effects of universal health insurance on health care utilization and supply-side responses: Evidence from Japan.” Journal of Public Economics 99: 123.

Krishnamurthi, Lakshman, Tridib Mazumdar, and S. P. Raj. (1992) “Asymmetric response to price in consumer brand choice and purchase quantity decisions." Journal of Consumer Research 19(3): 387-400.

Lin, Haizhen, and Daniel W. Sack. (2019) “Intertemporal substitution in health care demand: 
Evidence from the RAND Health Insurance Experiment” Journal of Public Economics 175: 2943.

Mazumdar, Tridib, S.P. Raj, and Indrajit Sinha (2005) "Reference price research: Review and propositions.” Journal of Marketing 69(4): 84-102.

OECD (2004) Private Health Insurance in OECD Countries, The OECD Health Project, OECD Publishing, Paris. https://doi.org/10.1787/9789264007451-en. (Last accessed on September 26, 2020).

Putler, Daniel S. (1992) “Incorporating reference price effects into a theory of consumer choice.” Marketing Science 11(3): 287-309.

Rice, Thomas. (2013) “The behavioral economics of health and health care.” Annual Review of Public Health 34(1): 431-447.

Tversky, Amos, and Daniel Kahneman. (1991) "Loss aversion in riskless choice: A referencedependent model.” The Quarterly Journal of Economics 106(4): 1039-1061. 
Table 1: Summary statistics

\begin{tabular}{|c|c|c|c|c|}
\hline Variable & Mean & SD & Min & Max \\
\hline \multicolumn{5}{|l|}{ A. Individual $(\mathrm{N}=59,775)$} \\
\hline \multicolumn{5}{|l|}{ Subsidy info } \\
\hline Number of subsidy status changes & 0.21 & 0.50 & 0 & 2 \\
\hline At least one subsidy status change & $16.6 \%$ & 0.37 & 0 & 1 \\
\hline At least one subsidy expansion (price “decrease”) & $15.5 \%$ & 0.36 & 0 & 1 \\
\hline At least one subsidy expiration (price “increase”) & $5.2 \%$ & 0.22 & 0 & 1 \\
\hline \multicolumn{5}{|l|}{ Characteristics } \\
\hline Female & $49.0 \%$ & 0.50 & 0 & 1 \\
\hline Age (in years) & 10.86 & 2.63 & 6.08 & 15.92 \\
\hline \multicolumn{5}{|l|}{ B. Per-moenth $(\mathrm{N}=2,027,910)$} \\
\hline \multicolumn{5}{|l|}{ Utilization } \\
\hline Total outpatient spending & 60.8 & 259.0 & 0.0 & 93355 \\
\hline Total outpatient spending (at least one visit) & 149.5 & 389.4 & 0.8 & 93355 \\
\hline OOP payment per visit without subsidy & 22.2 & 46.4 & 0.7 & 2293 \\
\hline \multicolumn{5}{|l|}{ Spending by type } \\
\hline Medication & 28.5 & 238.2 & 0.0 & 93244 \\
\hline Consultation fees & 13.8 & 24.3 & 0.0 & 466 \\
\hline Laboratory tests & 10.1 & 31.8 & 0.0 & 2261 \\
\hline Non-surgical procedures & 3.4 & 14.0 & 0.0 & 1246 \\
\hline Surgical procedures & 1.9 & 26.4 & 0.0 & 8045 \\
\hline Rest & 0.7 & 14.2 & 0.0 & 2832 \\
\hline
\end{tabular}

Notes: Outpatient spending, and out-of-pocket (OOP) payment are all measured in USD (100JPY/USD). 
Table 2: Main results

\section{Coeff Test}

\section{Long-term effects}

\begin{tabular}{|c|c|c|c|}
\hline (1) $\quad \beta^{d e c}$ & $\begin{array}{c}8.885 * * * \\
(2.254)\end{array}$ & H0: $\left|\beta^{\text {inc }}\right|-\left|\beta^{d e c}\right|=0$ & $\begin{array}{c}11.161^{* * *} \\
(2.618)\end{array}$ \\
\hline (1), $\beta^{i n c}$ & $\begin{array}{c}-20.046 * * * \\
(2.356)\end{array}$ & & \\
\hline
\end{tabular}

\section{$\underline{\text { Short-term effects }}$}

\begin{tabular}{|c|c|c|c|c|}
\hline (2) & $\gamma_{-1}^{d e c}$ (anticipation) & $\begin{array}{c}-15.192 * * * \\
(2.759)\end{array}$ & $\begin{array}{l}\text { (4) } \mathrm{H} 0:\left|\gamma_{-1}^{d e c}\right|-\left|\gamma_{0}^{d e c}\right|=0 \\
\text { (overshooting) }\end{array}$ & $\begin{array}{c}9.414^{* * *} \\
(2.722)\end{array}$ \\
\hline (3) & $\gamma_{0}^{d e c}$ (offset) & $\begin{array}{c}5.777 * * \\
(2.566)\end{array}$ & (4) $\begin{array}{l}\text { H0: }\left|\gamma_{-1}^{i n c}\right|-\left|\gamma_{0}^{i n c}\right|=0 \\
\text { (overshooting) }\end{array}$ & $\begin{array}{l}21.248 * * * \\
\quad(5.150)\end{array}$ \\
\hline (2)' & $\gamma_{-1}^{i n c}$ (anticipation) & $\begin{array}{l}28.219 * * * \\
(4.460)\end{array}$ & $\begin{aligned} \mathrm{H} 0: & \left\{\left|\gamma_{-1}^{i n c}\right|-\left|\gamma_{0}^{i n c}\right|\right\}- \\
& \left\{\left|\gamma_{-1}^{\text {dec }}\right|-\left|\gamma_{0}^{\text {dec }}\right|\right\}=0\end{aligned}$ & $\begin{array}{l}11.833 * * \\
(5.933)\end{array}$ \\
\hline (3)' & $\gamma_{0}^{\text {inc }}$ (offset) & $\begin{array}{c}-6.971 * * * \\
(2.490)\end{array}$ & & \\
\hline \multicolumn{2}{|c|}{ R-squared } & 0.52 & & \\
\hline \multicolumn{2}{|c|}{$\mathrm{N}$} & $2,027,910$ & & \\
\hline \multicolumn{2}{|c|}{$\mathrm{N}$ of Individual } & 59,775 & & \\
\hline
\end{tabular}

Notes: The estimates from equation [2] are reported. The outcome is the monthly spending on outpatient care measured in USD (100JPY/USD). "Price decrease (dec)" indicates the subsidy expansion which lowers the price of healthcare from 30\% to $0 \%$, and "Price increase (inc)" indicates subsidy expiration that raises the price from $0 \%$ to $30 \%$. All the regressions include age (in months) FE, time (in month) FE, and individual FE. We also control for an in-kind dummy that takes one if the municipality offers the subsidy in the form of in-kind instead of refund, and an income restriction dummy that takes one if the municipality imposes restriction for subsidy eligibility. Significance levels: ${ }^{* * *} \mathrm{p}<0.01,{ }^{* *} \mathrm{p}<0.05,{ }^{*} \mathrm{p}<0.10$ 


\section{Table 3: By service types}

\section{A. Long-term responsess}

\begin{tabular}{|c|c|c|c|c|c|}
\hline & & Medication & Consultation & $\begin{array}{c}\text { Laboratory } \\
\text { tests }\end{array}$ & $\begin{array}{c}\text { Non-surgical } \\
\text { procedures }\end{array}$ \\
\hline \multicolumn{6}{|c|}{$\underline{\text { Coefficients }}$} \\
\hline (1) & $\beta^{d e c}$ & $\begin{array}{c}5.674^{* * *} \\
(0.546)\end{array}$ & $\begin{array}{c}2.690 * * * \\
(0.382)\end{array}$ & $\begin{array}{c}2.927 * * * \\
(0.259)\end{array}$ & $\begin{array}{c}1.030 * * * \\
(0.136)\end{array}$ \\
\hline (1)' & $\beta^{\text {inc }}$ & $\begin{array}{c}-10.183 * * * \\
(0.935)\end{array}$ & $\begin{array}{c}-1.338 * * * \\
(0.496)\end{array}$ & $\begin{array}{c}-2.602 * * * \\
(0.696)\end{array}$ & $\begin{array}{c}-0.938 * * * \\
(0.270)\end{array}$ \\
\hline \multicolumn{6}{|l|}{ Test } \\
\hline & $\mathrm{H} 0:\left|\beta^{\text {inc }}\right|-\left|\beta^{\operatorname{dec}}\right|=0$ & $\begin{array}{c}4.509 * * * \\
(1.173)\end{array}$ & $\begin{array}{c}-1.352 * * \\
(0.626)\end{array}$ & $\begin{array}{l}-0.325 \\
(0.658)\end{array}$ & $\begin{array}{c}-0.092 \\
(0.268)\end{array}$ \\
\hline
\end{tabular}

B. Short-term responsess

\begin{tabular}{|c|c|c|c|c|c|}
\hline & & Medication & Consultation & $\begin{array}{c}\text { Laboratory } \\
\text { tests }\end{array}$ & $\begin{array}{l}\text { Non-surgical } \\
\text { procedures }\end{array}$ \\
\hline \multicolumn{6}{|c|}{$\underline{\text { Coefficients }}$} \\
\hline (2) & $\gamma_{-1}^{d e c}$ (anticipation) & $\begin{array}{c}-2.051 * * * \\
(0.733)\end{array}$ & $\begin{array}{c}-1.072 * * \\
(0.428)\end{array}$ & $\begin{array}{c}-1.790^{* * *} \\
(0.429)\end{array}$ & $\begin{array}{c}-0.455^{* * *} \\
(0.158)\end{array}$ \\
\hline (3) & $\gamma_{0}^{d e c}$ (offset) & $\begin{array}{c}0.826 \\
(1.113)\end{array}$ & $\begin{array}{c}0.421 \\
(0.370)\end{array}$ & $\begin{array}{c}2.062 * * * \\
(0.523)\end{array}$ & $\begin{array}{c}-0.409 * * \\
(0.163)\end{array}$ \\
\hline (2)' & $\gamma_{-1}^{\text {inc }}$ (anticipation) & $\begin{array}{l}12.563 * * * \\
(1.932)\end{array}$ & $\begin{array}{c}2.453^{* * *} \\
(0.596)\end{array}$ & $\begin{array}{c}7.819 * * * \\
(1.572)\end{array}$ & $\begin{array}{c}1.819 * * * \\
(0.491)\end{array}$ \\
\hline (3)' & $\gamma_{0}^{i n c}$ (offset) & $\begin{array}{c}-1.892 * * \\
(0.836)\end{array}$ & $\begin{array}{c}-2.317^{* * *} \\
(0.378)\end{array}$ & $\begin{array}{c}-1.572^{* * *} \\
(0.454)\end{array}$ & $\begin{array}{l}-0.276 \\
(0.239)\end{array}$ \\
\hline \multicolumn{6}{|c|}{ Tests } \\
\hline (4) & $\begin{array}{c}\text { H0: }\left|\gamma_{-1}^{\text {dec }}\right|-\left|\gamma_{0}^{\text {dec }}\right|=0 \\
\text { (overshooting) }\end{array}$ & $\begin{array}{c}1.225 \\
(1.647)\end{array}$ & $\begin{array}{c}0.651 \\
(0.529)\end{array}$ & $\begin{array}{l}-0.272 \\
(0.703)\end{array}$ & $\begin{array}{c}0.865^{* * * *} \\
(0.241)\end{array}$ \\
\hline (4)' & $\begin{array}{l}\text { H0: }\left|\gamma_{-1}^{i n c}\right|-\left|\gamma_{0}^{i n c}\right|=0 \\
\text { (overshooting) }\end{array}$ & $\begin{array}{c}10.67^{* * * *} \\
(2.209)\end{array}$ & $\begin{array}{c}0.137 \\
(0.692)\end{array}$ & $\begin{array}{c}6.247 * * * \\
(1.700)\end{array}$ & $\begin{array}{c}1.543^{* * *} \\
(0.500)\end{array}$ \\
\hline & $\begin{array}{l}\mathrm{H} 0:\left\{\left|\gamma_{-1}^{i n c}\right|-\left|\gamma_{0}^{i n c}\right|\right\}- \\
\left\{\left|\gamma_{-1}^{\text {dec }}\right|-\left|\gamma_{0}^{\text {dec }}\right|\right\}=0\end{array}$ & $\begin{array}{c}9.445^{* * *} \\
(2.648)\end{array}$ & $\begin{array}{l}-0.514 \\
(0.867)\end{array}$ & $\begin{array}{c}6.519 * * * \\
(1.926)\end{array}$ & $\begin{array}{c}0.678 \\
(0.562)\end{array}$ \\
\hline
\end{tabular}

Notes: The estimates from equation [2] are reported. The outcome is the monthly spending on outpatient care measured in USD (100JPY/USD). "Price decrease (dec)" indicates the subsidy expansion which lowers the price of healthcare from 30\% to $0 \%$, and "Price increase (inc)" indicates subsidy expiration that raises the price from $0 \%$ to $30 \%$. All the regressions include age (in months) FE, time (in month) FE, and individual FE. We also control for an in-kind dummy that takes one if the municipality offers the subsidy in the form of in-kind instead of refund, and an income restriction dummy that takes one if the municipality imposes restriction for subsidy eligibility. Significance levels: ${ }^{* * *} \mathrm{p}<0.01,{ }^{* *} \mathrm{p}<0.05,{ }^{*} \mathrm{p}<0.10$ 


\section{Figure 1: Theoretical Underpining}

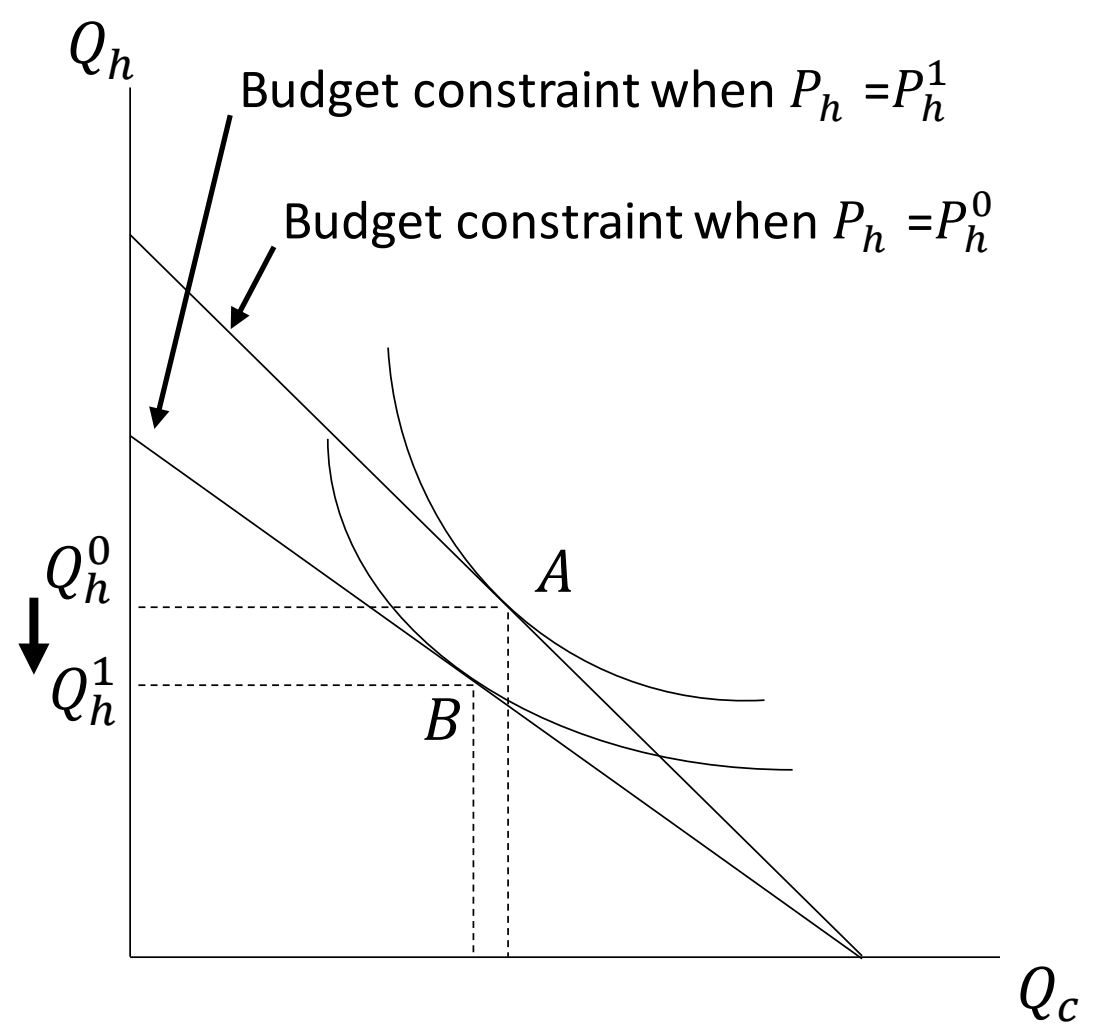

Notes: The figure illustrates the textbook case of a consumer's decision, where the consumer chooses the amounts of two goods, healthcare service $Q_{h}$ and a composite good $Q_{c}$, given the prices of the two goods $\left(P_{h}\right.$ and $P_{c}$ ) under a budget constraint. The initial prices and quantities of the two goods are given by $\left(P_{h}^{0}, Q_{h}^{0}\right)$ and $\left(P_{c}^{0}, Q_{c}^{0}\right)$, respectively. If the price of healthcare service increases from $P_{h}^{0}$ to $P_{h}^{1}$, its quantity will decrease from $Q_{h}^{0}$ to $Q_{h}^{1}$ based on the income and substitution effects. Now, suppose that the change in the price of healthcare service is reversed from $P_{h}^{1}$ to $P_{h}^{0}$. Then, based on classical demand theory, the quantity of healthcare service will return to the original quantity, $Q_{h}^{0}$, from $Q_{h}^{1}$. That is, the absolute value of the impact of the price change on demand should be the same regardless of the direction of the price change. By contrast, under loss aversion, utility loss from a price increase is greater than the utility gain from a price decrease even when the size of the price change is the same. This, in turn, leads to a prediction that the magnitude of the quantity change will be greater when the price increases from $P_{h}^{0}$ to $P_{h}^{1}$ than when it decreases from $P_{h}^{1}$ to $P_{h}^{0}$. 


\section{Figure 2: Time series of maximum age covered by healthcare subsidy}

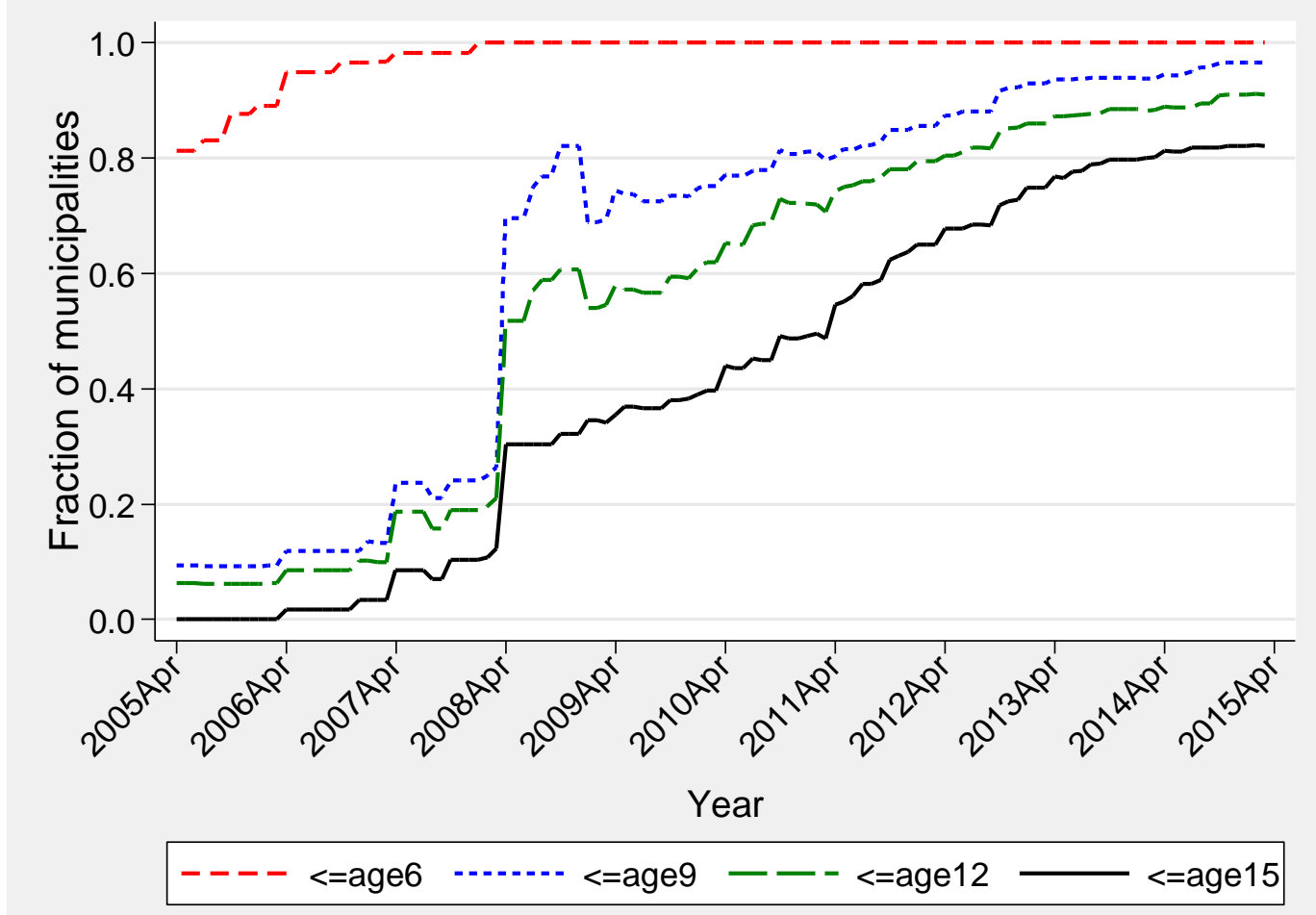

Notes: The figure plots the share of municipalities in our insurance claims data by the maximum age for the subsidy eligibility for outpatient care at the monthly level during April 2005-March 2015. There are total of 165 municipalities. 
Figure 3: Event study

Price decrease $(30 \% \rightarrow 0 \%)$

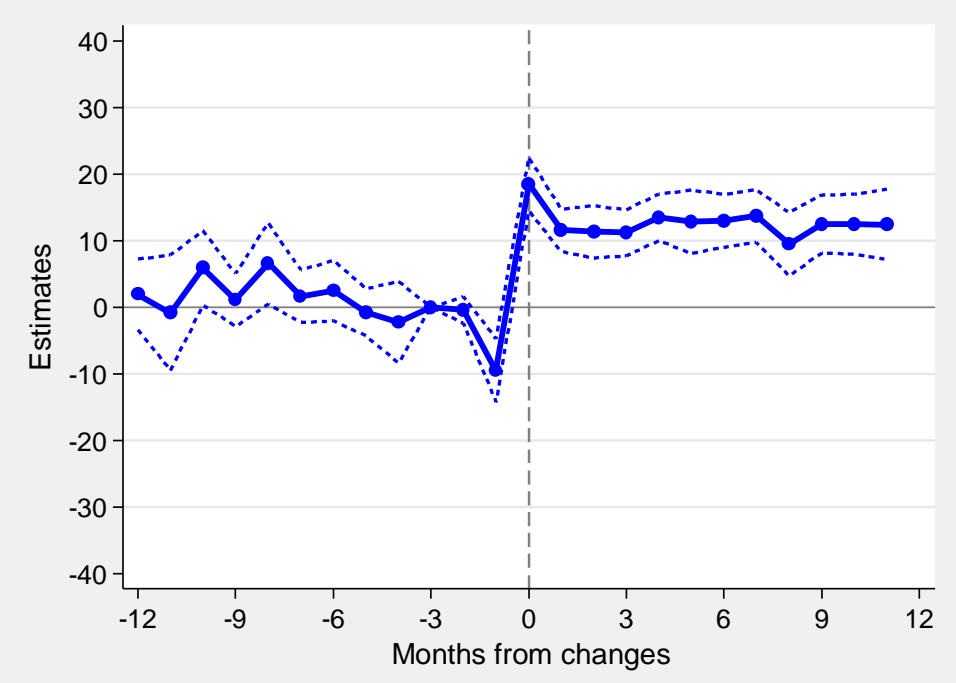

Price increase $(0 \% \rightarrow 30 \%)$

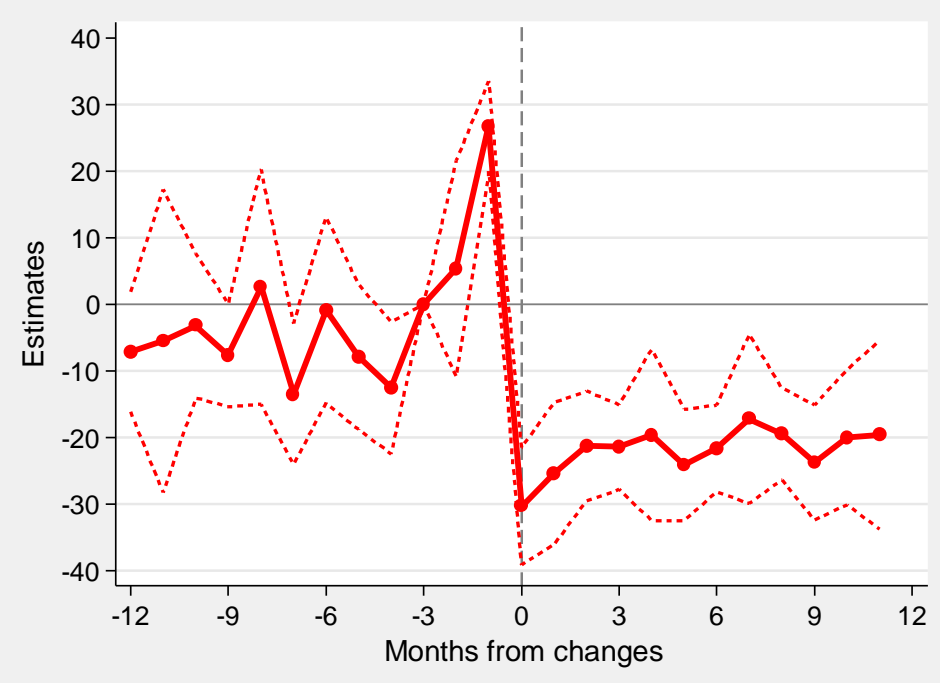

Notes: The outcome is the monthly spending on outpatient care measured in USD (100JPY/USD). "Price decrease" indicates the subsidy expansion which lowers the price of healthcare from $30 \%$ to $0 \%$, and "Price increase" indicates subsidy expiration that raises the price from $0 \%$ to $30 \%$. The solid lines plot the estimates from a variant of estimation equation [2] where the subsidized dummy is replaced by the interaction of belonging to the treatment group (i.e., experiencing the change in subsidy status) and a series of dummies for each month, ranging from 12 months prior to the change in subsidy status to 12 months after the change ( $T=-12$ to +11 , where $T=0$ is the change in subsidy status). The dotted lines are the 95th confidence intervals where standard errors clustered at municipality level are used to construct them. The reference month is three months before the change (T=-3). The scales of the $y$ axis are set as the same so that the two figures for opposite price change directions are visually comparable. 
Figure 4: Stylized Demand Resonses

Price decrease $(30 \% \rightarrow 0 \%)$

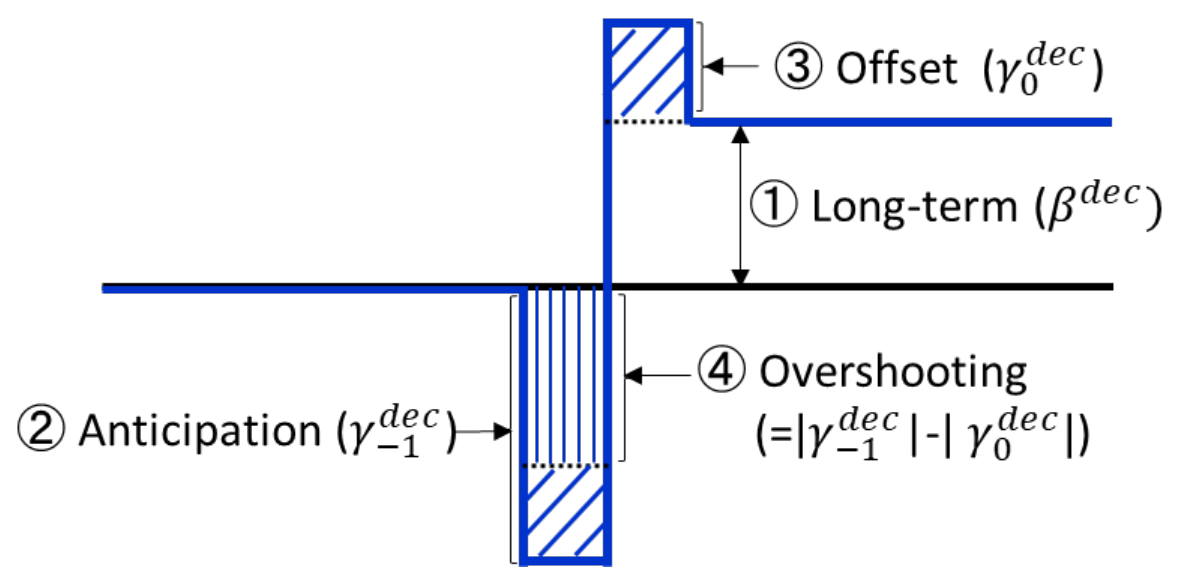

Price increase $(0 \% \rightarrow 30 \%)$

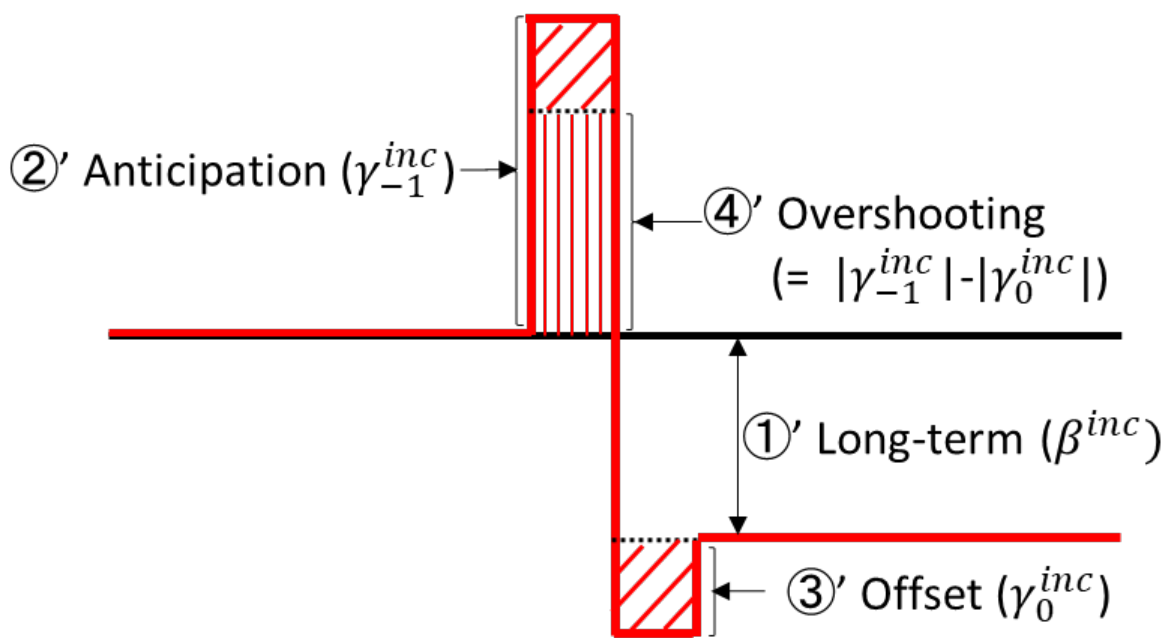

Notes: The figures present a stylized model of demand responses. The figure on the left corresponds to price decreases (from $30 \%$ to $0 \%$ ) and the one on the right is for price increases (from $0 \%$ to 30\%). "Long-term response (1) and (1)')" reflects the long-term demand changes as the price changes, which are parameterized as $\beta^{\text {dec }}$ on the left, and $\beta^{i n c}$ on the right. "Anticipatory effect (2) and (2)')" reflects the short-term demand change immediately before the price change at $T=-1$, which are parameterize as $\gamma_{-1}^{\text {dec }}$ on the left, and $\gamma_{-1}^{\text {inc }}$ on the right. "Offset effect (3) and (3)' )" reflects the short-term demand change immediately after the price change at $T=0$, which are parameterized as $\gamma_{0}^{d e c}$ on the left, and $\gamma_{0}^{\text {inc }}$ on the right. Finally, "over-shooting (4) and (4)')" is the difference between the anticipation effect and the offset effect, i.e., $\left(\left|\gamma_{-1}^{\text {dec }}\right|-\left|\gamma_{0}^{\text {dec }}\right|\right)$ on the left, and $\left(\left|\gamma_{-1}^{\text {inc }}\right|-\left|\gamma_{0}^{\text {inc }}\right|\right)$ on the right. 
Figure 5: Event study by service categories

Price decrease $(30 \% \rightarrow 0 \%$ )

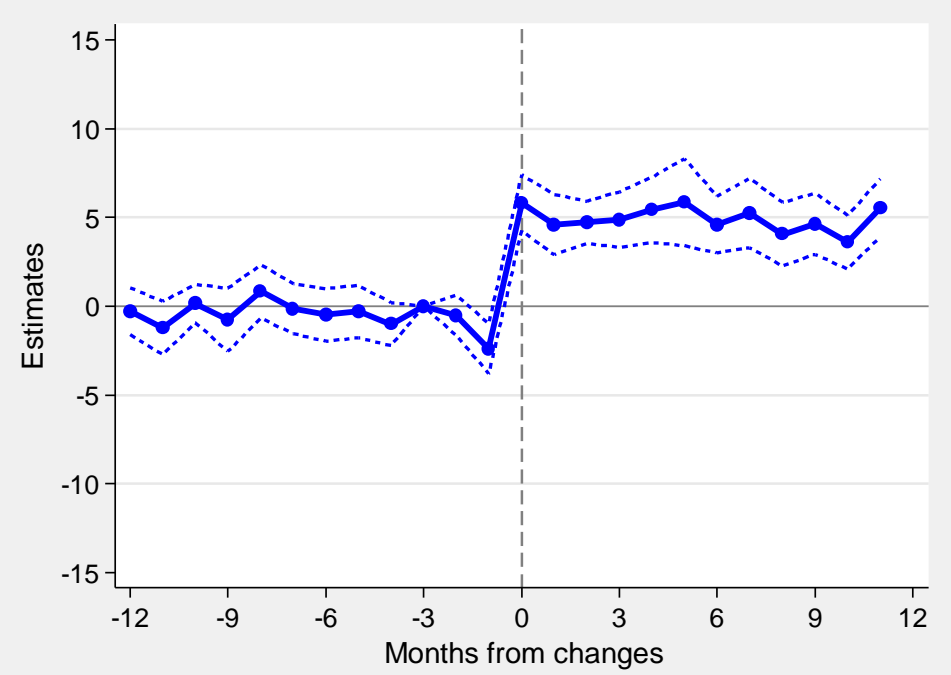

A. Medication

Price increase $(0 \% \rightarrow 30 \%)$

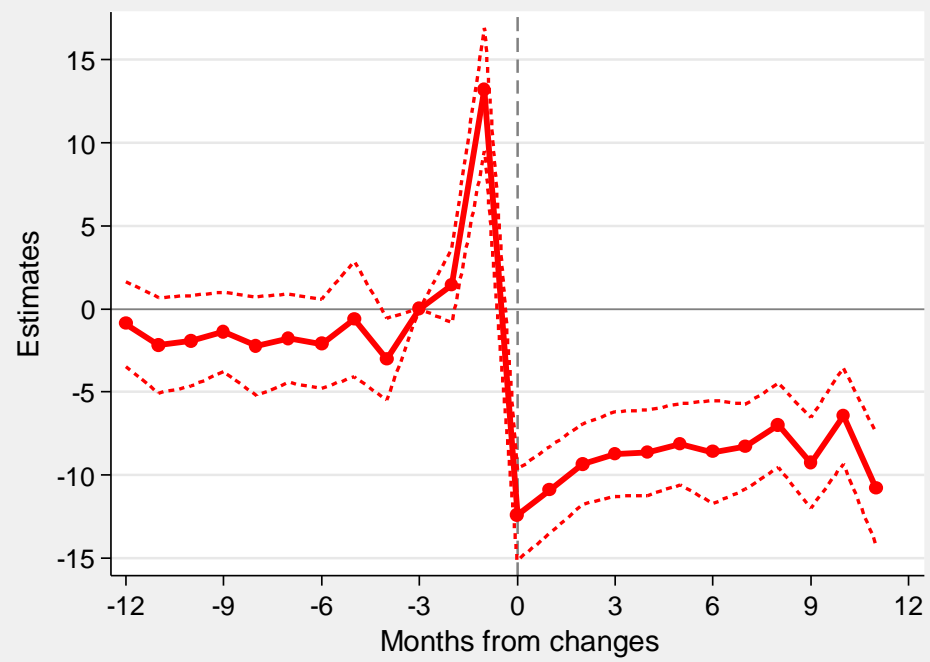

\section{B. Consultation fees}

Price decrease $(30 \% \rightarrow 0 \%$ )

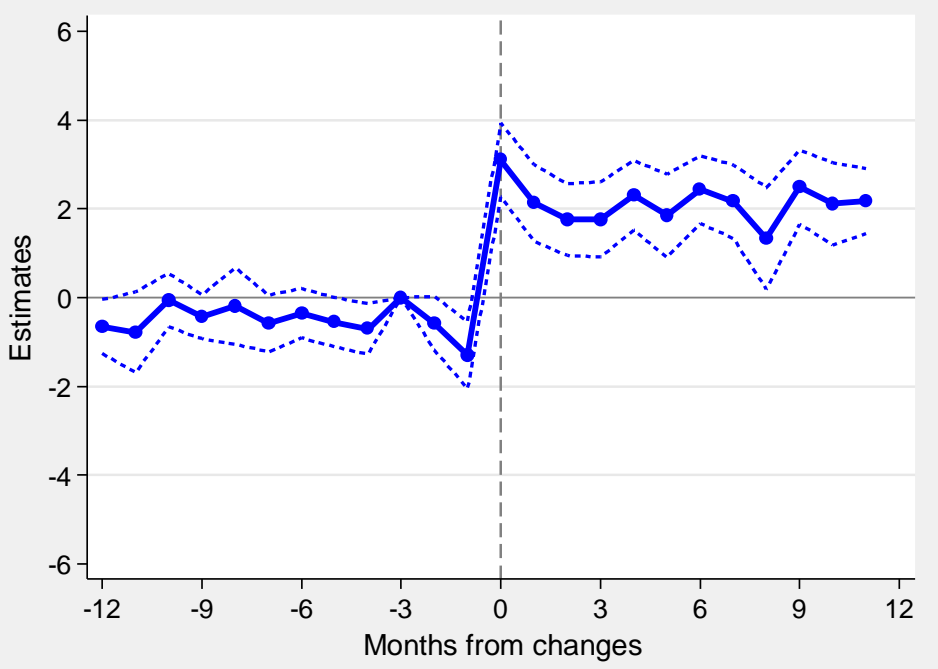

Price increase $(0 \% \rightarrow 30 \%)$

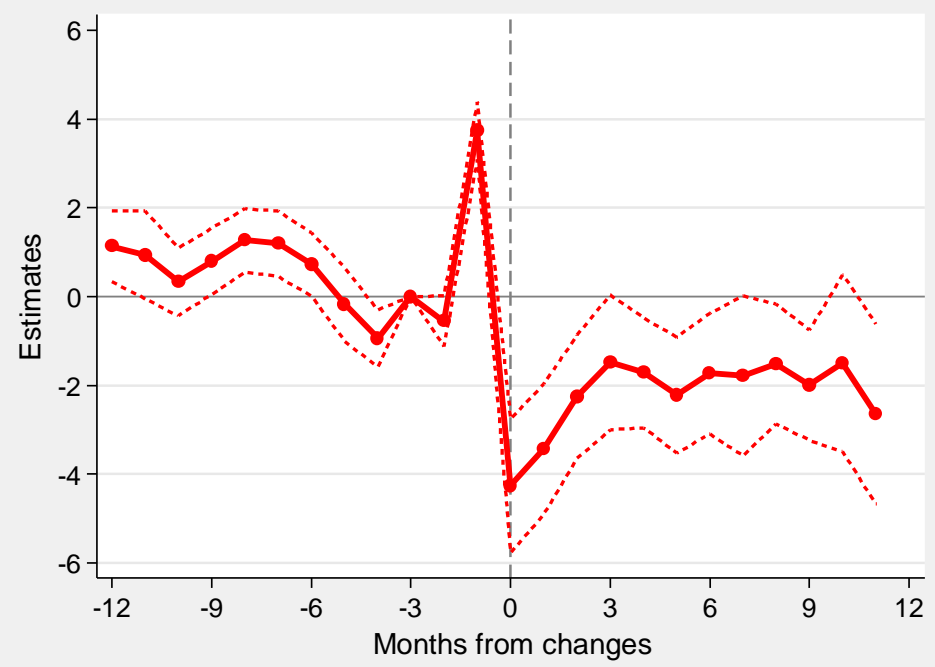


Price decrease $(30 \% \rightarrow 0 \%)$

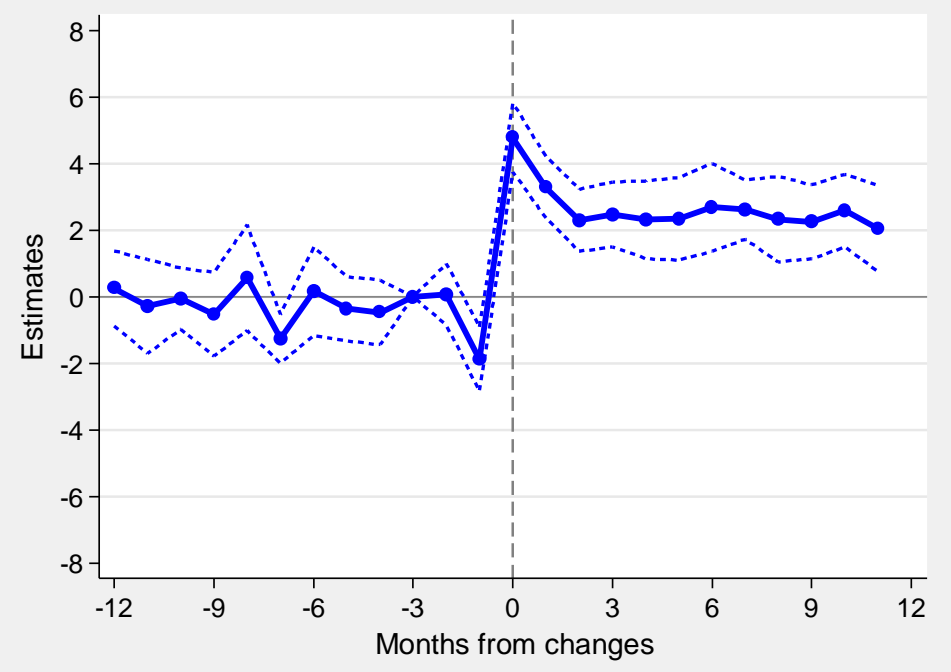

\section{Laboratory tests}

Price increase $(0 \% \rightarrow 30 \%)$

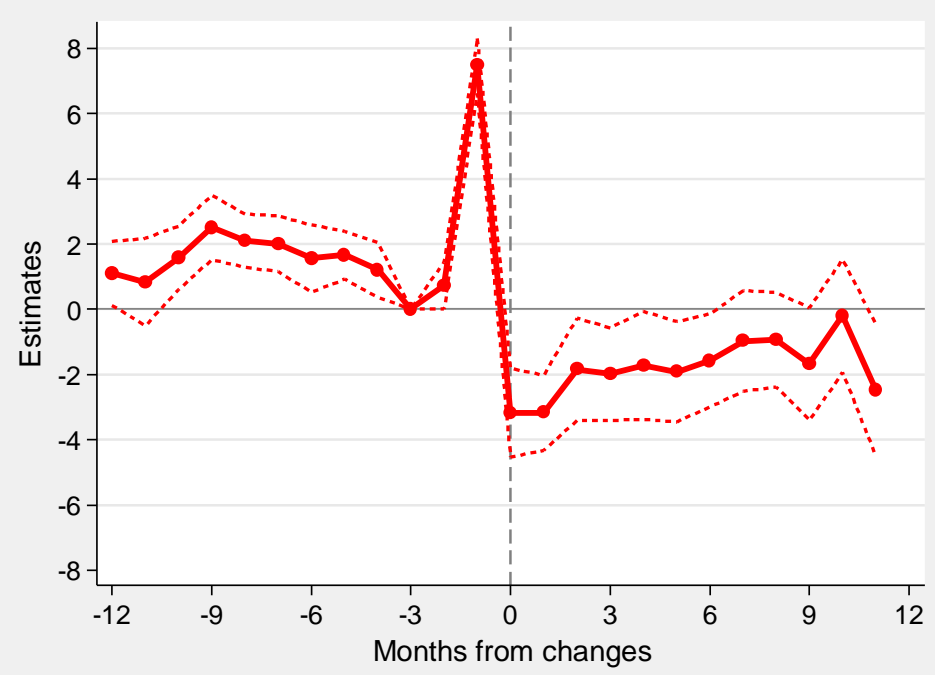

D. Non-surgical procedures

Price decrease $(30 \% \rightarrow 0 \%)$

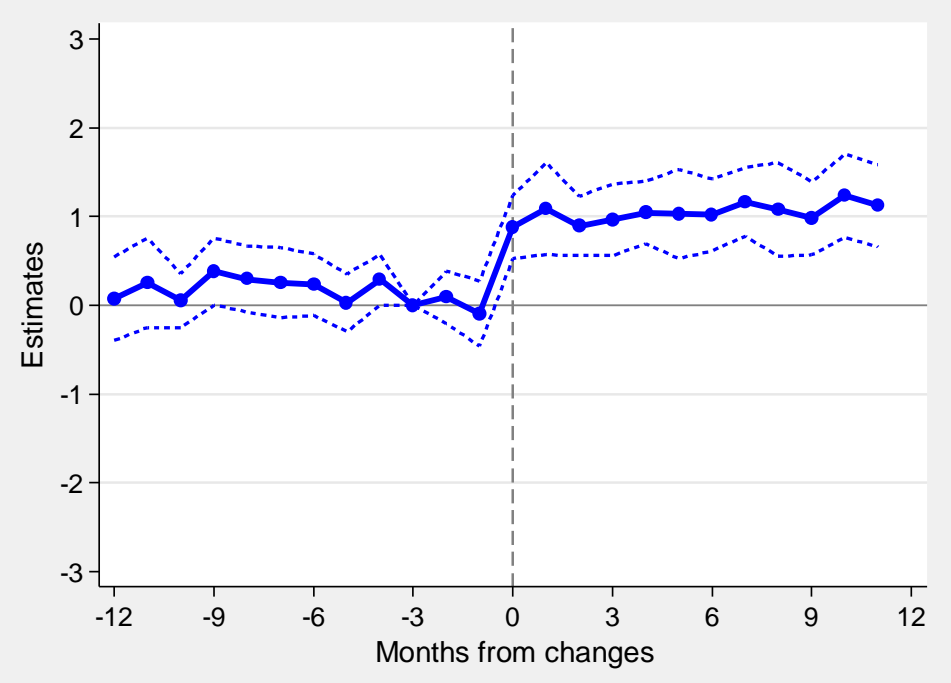

Price increase $(0 \% \rightarrow 30 \%)$

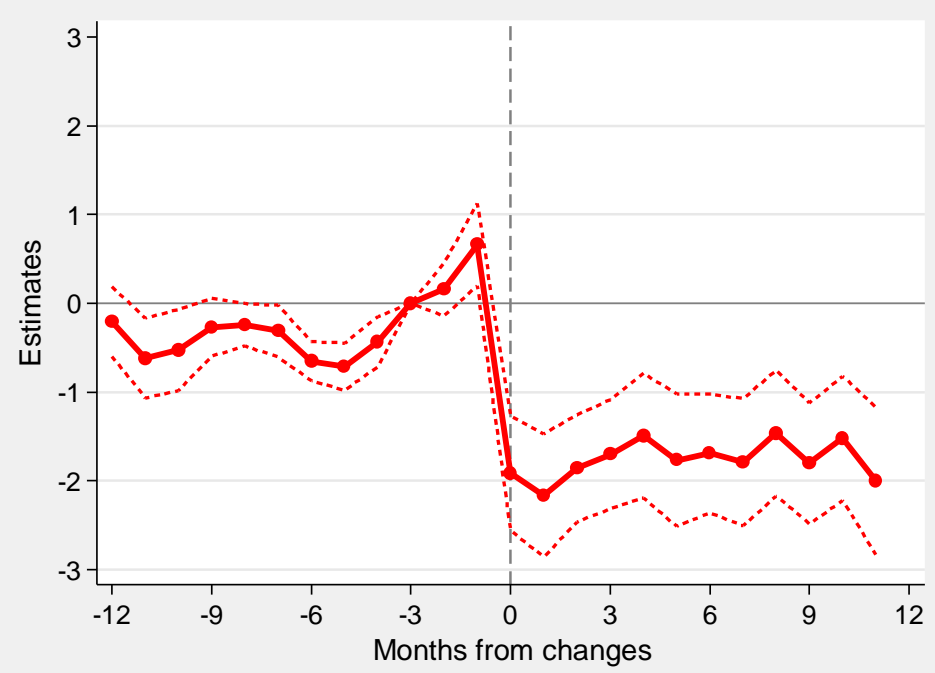

Notes: The outcome is the monthly spending on outpatient care measured in USD (100JPY/USD). "Price decrease” indicates the subsidy expansion which lowers the price of healthcare from $30 \%$ to $0 \%$, and "Price increase" indicates subsidy expiration that raises the price from $0 \%$ to $30 \%$. The solid lines plot the estimates from a variant of estimation equation [2] where the subsidized dummy is replaced by the interaction of belonging to the treatment group (i.e., experiencing the change in subsidy status) and a series of dummies for each month, ranging from 12 months prior to the change in subsidy status to 12 months after the change ( $T=-12$ to +11 , where $T=0$ is the change in subsidy status). The dotted lines are the 95th confidence intervals where standard errors clustered at municipality level are used to construct them. The reference month is three months before the change (T=-3). The scales of the $y$ axis are set as the same so that the two figures for opposite price change directions are visually comparable. 


\section{Appendix Tables and Figures}

\section{Table A1: Robustness checks}

\begin{tabular}{|c|c|c|c|c|}
\hline & & Coeff & Test & \\
\hline \multicolumn{5}{|c|}{ Long-term effects } \\
\hline (1) & $\beta^{d e c}$ & $\begin{array}{c}9.295^{* * *} \\
(3.136)\end{array}$ & $\mathrm{H} 0:\left|\beta^{i n c}\right|-\left|\beta^{d e c}\right|=0$ & $\begin{array}{c}6.813 * * \\
(3.165)\end{array}$ \\
\hline (1)' & $\beta^{\text {inc }}$ & $\begin{array}{c}-16.108 * * * \\
(2.878)\end{array}$ & & \\
\hline \multicolumn{5}{|c|}{ Short-term effects } \\
\hline & $\gamma_{-1}^{d e c}$ (anticipation) & $\begin{array}{c}-11.923 * * * \\
(2.571)\end{array}$ & $\begin{array}{l}\text { (4) } \mathrm{H} 0:\left|\gamma_{-1}^{d e c}\right|-\left|\gamma_{0}^{d e c}\right|=0 \\
\text { (overshooting) }\end{array}$ & $\begin{array}{c}7.27 * \\
(3.928)\end{array}$ \\
\hline & $\gamma_{0}^{d e c}$ (offset) & $\begin{array}{l}4.653 * \\
(2.487)\end{array}$ & $\begin{array}{l}\text { (4) } \mathrm{H} 0:\left|\gamma_{-1}^{i n c}\right|-\left|\gamma_{0}^{i n c}\right|=0 \\
\text { (overshooting) }\end{array}$ & $\begin{array}{c}27.391^{* * *} \\
\quad(4.748)\end{array}$ \\
\hline (2)' & $\gamma_{-1}^{i n c}$ (anticipation) & $\begin{array}{l}33.593 * * * \\
(4.102)\end{array}$ & $\begin{aligned} \mathrm{H} 0: & \left\{\left|\gamma_{-1}^{i n c}\right|-\left|\gamma_{0}^{i n c}\right|\right\}- \\
& \left\{\left|\gamma_{-1}^{\text {dec }}\right|-\left|\gamma_{0}^{\text {dec }}\right|\right\}=0\end{aligned}$ & $\begin{array}{l}20.121^{* * *} \\
\quad(6.265)\end{array}$ \\
\hline (3)' & $\gamma_{0}^{i n c}$ (offset) & $\begin{array}{l}-6.202^{* *} \\
(2.614)\end{array}$ & & \\
\hline \multirow{2}{*}{\multicolumn{2}{|c|}{$\begin{array}{l}\text { R-squared } \\
\mathrm{N}\end{array}$}} & 0.52 & & \\
\hline & & $2,023,495$ & & \\
\hline \multicolumn{2}{|c|}{$\mathrm{N}$ of Individual } & 63,589 & & \\
\hline
\end{tabular}

Notes: The estimates from equation [2] which also includes time-by-municipality FE are reported. The outcome is the monthly spending on outpatient care measured in USD (100JPY/USD). "Price decrease (dec)" indicates the subsidy expansion which lowers the price of healthcare from $30 \%$ to $0 \%$, and "Price increase (inc)" indicates subsidy expiration that raises the price from $0 \%$ to $30 \%$. All the regressions include age (in months) FE, time (in month) FE, and individual FE. We also control for an in-kind dummy that takes one if the municipality offers the subsidy in the form of in-kind instead of refund, and an income restriction dummy that takes one if the municipality imposes restriction for subsidy eligibility. Significance levels: ${ }^{* * *} \mathrm{p}<0.01,{ }^{* *} \mathrm{p}<0.05,{ }^{*} \mathrm{p}<0.10$ 